\title{
Tratamiento mediático de los resultados educativos en la prensa peruana
}

\author{
Osbaldo Turpo Gebera
}

Universidad Nacional de San Agustín de Arequipa. Perú. oturpo@unsa.edu.pe

Recibido: $18 / 5 / 2019$

Aceptado: $16 / 1 / 2020$

Publicado: 20/7/2020

\section{Resumen}

El tratamiento informativo de los resultados educativos desvela aspectos fundamentales de las políticas pedagógicas. Este estudio reconoce las representaciones mediáticas que la prensa peruana construye sobre las evaluaciones internacionales (PISA 2015; TERCE 2013) y nacionales (ECE 2016) desde las notas informativas de los principales diarios impresos en versión digital. El proceso metodológico siguió un análisis interpretativo de los contenidos cuantificados y recuperados de los repositorios periodísticos. En ese sentido, se organizó la información extraída en textos o unidades de significación, las mismas que fueron reproducidas como valores noticia. Los resultados confirman el predominio de las representaciones mediáticas de la prueba PISA sobre la prueba ECE y la relegación de TERCE, consecuencias expresadas a través de mensajes sobre el fracaso del sistema educativo nacional, que lo situaban en los últimos puestos de la clasificación, obviaban sus mejoras y generaban un sentido de alarma social como evidencia de la mediatización y la politización de las evaluaciones educativas.

Palabras clave: evaluación de estudiantes; medios de comunicación de masas; papel de la educación; uso de la información; clasificación

\section{Resum. Tractament mediàtic dels resultats educatius en la premsa peruana}

El tractament informatiu dels resultats educatius revela aspectes fonamentals de les polítiques pedagògiques. Aquest estudi reconeix les representacions mediàtiques que la premsa peruana construeix sobre les avaluacions internacionals (PISA 2015 y TERCE 2013) i nacionals (ECE, 2016) des de les notes informatives dels principals diaris impresos en versió digital. El procés metodològic va seguir una anàlisi interpretativa dels continguts quantificats i recuperats dels dipòsits periodístics. En aquest sentit, es va organitzar la informació extreta en textos o unitats de significació, les mateixes que van ser reproduïdes com a valors notícia. Els resultats confirmen el predomini de les representacions mediàtiques de la prova PISA sobre la prova ECE i el relegament de TERCE, consequiències expressades a través de missatges sobre el fracàs del sistema educatiu nacional, que el situaven en els últims llocs del rànquing, n'obviaven les millores i generaven un sentit d'alarma social com a evidència de la mediatització i la politització de les avaluacions educatives.

Paraules clau: avaluació d'estudiants; mitjans de comunicació de massa; paper de l'educació; ús de la informació; rànquing 


\title{
Abstract. Media treatment of educational outcomes in the Peruvian press
}

The informative treatment of educational outcomes reveals fundamental aspects of educational policies. This study examines media representations of international (PISA 2015 and TERCE 2013 for Latin America) and national (ECE 2016 for Peru) assessments constructed by the Peruvian press through informative notes of digital versions of the main printed periodicals. The methodology used was interpretative analysis of the quantified contents obtained from newspaper repositories. The information was extracted and organized in texts or units of significance, which were reproduced as news-values. The results confirm the predominance of media representations of the PISA test over the ECE and the relegation of TERCE. The mediatization and politicization of educational evaluations are expressed through messages about the failure of the national education system that highlight the last positions in the ranking, ignore improvements and generate a sense of social alarm.

Keywords: student assessment; mass media; role of education; use of information; ranking

\author{
Sumario \\ 1. Introducción 4. Conclusiones \\ 2. Método Referencias bibliográficas
}

3. Resultados

\section{Introducción}

La educación representa un campo político-ideológico y mediático de amplias tensiones: político, al generar disputas sobre las bases ideológicas que sustentan la educación y que, fundamentalmente, en los últimos tiempos vienen impuestas por el modelo neoliberal (Santa Cruz y Olmedo, 2012), y mediático, por reflejar a través de las «imágenes y textos en portada, un punto de vista para interpretar los eventos sociales relacionados con el campo educativo» (Cabalin y Antezana, 2016, p. 204). Tales situaciones conllevan a la mediatización del conocimiento como instancia para comprender a la sociedad dosificada en la que estamos incursos y que ha supuesto, según Verón (1998), la incorporación progresiva de nuevos registros significativos. En ese discurrir emergen los resultados educativos, más propiamente de las evaluaciones del aprendizaje, mediante las pruebas nacionales e internacionales como nuevos sistemas simbólicos para comunicar, representar y vehiculizar la cognición, al «articularse con aquellos elementos, fijando provisoriamente su sentido y vinculándose con determinado ordenamiento social» (Colella y Díaz, 2017, p. 462).

En los medios de prensa convienen política e ideología al representar aspectos trascendentes y de interés público, para lo cual recurren a representaciones mediáticas mediante encuadres informativos que centran una "mirada" predominante sobre el discurrir de la educación. Es evidente que la forma en que se aborda la noticia (tratamiento informativo) incide en la concepción asumida por la audiencia, tanto como el emplazamiento mediático asumido de rol 
de agente formador de opinión pública de los medios de comunicación de masas (Ronzani et al., 2009). De ese modo facilitan «con sus imágenes y textos en portada, un punto de vista para interpretar los eventos sociales relacionados con el campo educativo" (Cabalin y Antezana, 2015, p. 204), legitimando, con su fuerza performativa (Reguillo, 2007), lo que se debe entender en torno a un orden, un modelo o una práctica (Santa Cruz, 2016) simbólico.

La mediatización de la información contiene un alto interés político, al modificar las relaciones sociales a todo nivel, tanto en las instituciones como entre los actores sociales (Hjarvard, 2013; Verón, 1997), de ahí el interés por su estudio, de explicitar la producción selectiva de discursos y representaciones que gravitan en las nociones de lo visible u omisible (Carmona y Jaimes, 2015; Popp y Mendelson, 2010). Para Couldry (2012) y Rawolle y Lingard (2010), la mediatización sitúa a los sistemas educativos dentro de la «mediatización de la educación", tornando a los medios como protagonistas en la definición de las políticas educativas y, por ende, en la producción y difusión de sus discursos políticos, tanto que su campo de abordaje va más allá del ámbito escolar, al vincularla con las estructuras sociales, políticas y económicas. De ese modo, la educación adquiere relevancia simbólica, y sus representaciones marcan las definiciones que se adoptan (Cabalin y Antezana, 2016). Este proceso de mediatización ha significado una mayor participación de los medios en las políticas públicas en educación, influyendo considerablemente en el diseño, tanto como en la producción, de discursos e imágenes policéntricas y altamente simbólicas (Bowe, Ball y Gold, 1992; Lingard, 2016; Esser y Strrömbäck, 2014; Koh, 2009).

En ese orden de cambios, la mediatización promueve el influjo y el flujo de la noticia, posibilitando la (re)creación de los hechos acaecidos en la realidad educativa y la trasmisión de una visión como «la visualización de las políticas educativas» (Koh, 2009). En ese sentido, la prensa instituye unas estructuras de poder que naturalizan los efectos compartidos, impactando en las personas, atrayendo a nuevos lectores y resumiendo la noticia mediante estrategias narrativas que colaboran con la hegemonía simbólica de la información (Mateos y Gaona, 2018). Tales representaciones se configuran desde las estructuras informativas dominantes y desde la priorización de ciertas «lecturas» sobre la cotidianidad, aceptadas y asumidas como ciertas y válidas sobre la realidad trasmitida. Para los medios, las evaluaciones educativas simbolizan un «codiciado» objeto de representación, construido mediáticamente en diversos grados para incitar adhesiones o rechazos ciudadanos y para que circulen como «imágenes» definidas intencionalmente. Traducen, así, formas de interpretación de los resultados educativos (Turpo-Gebera, 2018a).

El carácter complejo del proceso educativo y de sus considerables consecuencias en los ciudadanos obedece a un proceso que «no depende de un solo factor (la escuela), sino de la interacción de varios factores: la escuela por supuesto, pero también [otros]» (Baudelot y Leclercq, 2008, p. 29). Los resultados mediáticos merecen una reflexión especial, por cuanto conciernen al conjunto de la sociedad y a los estamentos de la política y del gobierno. Pro- 
piamente, los resultados del aprendizaje de los estudiantes en las evaluaciones nacionales e internacionales suscitan un conjunto de reacciones y de prácticas discursivas de distintos ámbitos, entre ellos la prensa. De ahí su importancia para la sociedad, en tanto expresan las preocupaciones y las intenciones que las políticas educativas deberían concretar.

La dinámica informativa lleva a la confluencia de representaciones mediáticas que van desde lo informativo hasta la crítica, el encubrimiento, la sátira o el sensacionalismo como "respuesta ciudadana, es decir, su capacidad propositiva» (Díaz-Nosty, 2015, p. 14). En el ámbito educativo, los resultados de su intervención se manifiestan, esencialmente, a través de las evaluaciones de aprendizaje como expresiones de logro y, por consiguiente, de la calidad del sistema educativo. El proceso evaluativo permite tomar conocimiento de la necesidad de mantener o realizar cambios formativos, sea en la cobertura de la matricula o en los contenidos (Ravela, 2006). Los resultados divulgados constituyen una muestra de la eficacia, la cobertura, la satisfacción, etc. del sistema educativo como indicadores visibles y resumidos de la política pedagógica (Ferrer, Massot y Ferrer, 2006).

El tratamiento informativo que la prensa configura sobre los resultados educativos puede generar niveles de satisfacción o sinsabores ciudadanos sobre las evaluaciones, al desvelar la realidad socioeducativa o, más propiamente, mostrar la asociación de los factores escolares y de determinados aprendizajes con el contexto sociocultural, tanto como las diferencias de organización curricular, de periodización y dedicación escolar. En esencia, los resultados educativos enuncian las formas de producción y reproducción del mundo social (Vasilachis de Gialdino, 1997), que, en su criterio, resultan de relevante interés para la ciudadanía y la clase política y que los medios de prensa (re)crean mediáticamente según sus concepciones interpretativas (Rodrigo, 2015).

En los últimos años, los sistemas educativos se implican cada vez más con las pruebas internacionales de evaluación de aprendizajes, lo que revela su creciente interés en la evaluación de sus sistemas educativos. De ahí el interés de abordarlas, de analizar y reconocer las orientaciones que muestran los medios periodísticos. Perú participa en las evaluaciones internacionales auspiciadas por la Organización para la Cooperación y el Desarrollo Económicos (OCDE) a través de la prueba PISA (Programme for International Student Assessment) desde el año 2000 (2001 plus) hasta la actualidad, interrumpida en 2003 y en 2006. A nivel de América Latina forma parte de la evaluación del Laboratorio Latinoamericano de Evaluación de la Calidad de la Educación (LLECE), que el 2013 se concretó a través del Tercer Estudio Regional Comparativo y Explicativo (TERCE), dirigida por la Oficina Regional de Educación de la UNESCO para América Latina y el Caribe (OREALC/UNESCO), y también estuvo en estudios anteriores (PERCE y SERCE). A nivel nacional, desde el 2007, la Unidad de Medición de la Calidad (UMC), adscrita al Ministerio de Educación (MINEDU), aplica anualmente la prueba ECE (Evaluación Censal de Estudiantes). 


\subsection{Los resultados educativos en la prensa}

En el tratamiento informativo de los resultados educativos, según Ravela (2006), los medios no utilizan procedimientos de análisis adecuados, al desconocer la visión estratégica del Estado sobre el rol de la evaluación educativa. Por ende, las noticias se comparten de modo imperceptible, con representaciones que no siempre revelan interpretaciones consistentes y legítimas, sino comentarios ingenuos y genéricos, con datos inconsistentes y sin rigurosidad. Para Luzón y Torres (2013) el impacto mediático se concentra en la clasificación de países, de clasificaciones valorativas que confrontan realidades disímiles, desmereciendo los avances de los últimos de la clasificación. De esa manera soslayan su comprensión e incitan a realizar juicios inapropiados y a deformar «la percepción que la población general puede tener sobre la situación educativa» (Runte-Geidel, 2016, p. 730). En esa línea, muestran una visión de condena al sistema educativo que resulta descontextualizada, puesto que no vislumbran la historia de cambios socioeducativos, al enfatizar en opiniones sesgadas y superficiales que devienen en un "amarillismo» de la prensa (Munguía, 2019).

Ferrer, Massot y Ferrer (2006) sostienen que los medios, por lo general, recrean representaciones catastrofistas y de crisis, reproduciendo «una imagen negativa de las evaluaciones externas en general, [sin] una mayor ampliación y por ende profundización en el tema» (p. 156). Las noticias son presentadas como informaciones incompletas o precipitadas, sin mayor contraste ni análisis técnico, y recrean una visión sesgada e instigadora de interpretaciones dudosas (Báez Martín, 2016). Así, las representaciones noticiosas imponen «lecturas» ideológicas que evidencian un sentido de caos educativo, al responder a una configuración discursiva simplista, superficial, alarmista y limitada para una comprensión "auténtica» de la noticia (Rodrigo-Alsina y LazcanoPeña, 2014). Propiamente, el énfasis informativo se centra en los malos resultados, promoviendo la búsqueda de culpables y la sugerencia de reformas no siempre pertinentes.

En sentido inverso, para Rodríguez (2005) y González-Mayorga, Vidal y Vieira (2017), la prensa destaca en su tratamiento una ponderación pertinente de los resultados, al valorar de manera justa los factores que distinguen a los sistemas educativos de los países estudiados, puesto que consideran causas como la formación docente, las políticas pedagógicas, etc. Los autores sostienen que las comparaciones mejoran los sistemas educativos, al considerar los estilos y los niveles de desarrollo alcanzados y estimando las distancias que los separan de los estándares de evaluación. Para ellos, las clasificaciones han puesto en discusión la calidad de los sistemas educativos, puesto que han dado apertura a un mayor debate, pero sin la amplitud informativa ni el uso conveniente de los resultados. Tales situaciones conducirían a un entendimiento "aislado o solamente conocido por un sector pequeño de interesados» (Bustamante, 2017, p. 14), sin un encuentro balanceado y horizontal.

Las evaluaciones educativas, como PISA, permiten reconocer las construcciones noticiosas a partir de los géneros periodísticos que las abordan. Siguien- 
do a González-Mayorga, Vidal y Vieira (2017), el énfasis predominante de las noticias publicadas sobre PISA en España son de carácter informativo, semejante a lo encontrado en Perú por Turpo-Gebera (2018a). Los énfasis mediáticos remiten a un sentido descriptivo sobre la evaluación. En ambos contextos, los artículos de opinión periodística están subrepresentados en los medios, y son suscritos por periodistas o expertos procedentes de sectores no educativos, mientras que la presencia de pedagogos o profesionales de la educación es escasa. Visto técnicamente, PISA constituye «un instrumento de planificación educativa y en una potente base de datos que contribuye en la elaboración de análisis, investigaciones e informes gubernamentales que inciden en la orientación de las decisiones» (Rodrigo, 2019, p. 74), un aspecto escasamente relevado por la prensa, al adolecer de opiniones técnicas sobre las evaluaciones educativas.

Cuando la OCDE publica los resultados, por ejemplo, de PISA, la atención mediática genera una avalancha informativa (Runte-Geidel, 2016) que ECE no suscita tan contundentemente, salvo ciertas intencionalidades políticas, para generar disputa sobre "las responsabilidades de los gestores educativos. Debate que atraviesa además todos los formatos y tipos de medios (radio, televisión, prensa, Internet), logrando ser parte de la agenda mediática y de la opinión pública» (Baltazar y Gargurevich, 2017, p. 55). La vorágine de noticias sobre PISA provoca discusiones singulares sobre el acontecer educativo nacional que no siempre tienen un efecto favorecedor. Un análisis mediático y político revelaría que «el carácter y el tono de estas noticias, [...] seguramente influyen sobre la opinión pública y, principalmente, por la presión que ambas, noticias y opinión pública, pueden ejercer sobre las políticas educativas locales» (Runte-Geidel, 2016, p. 714).

Los antecedentes investigativos resumidos exponen un tratamiento informativo donde se privilegia la influencia de unas acciones y la irrelevancia de otras (Ruiz, Brändle y Cáceres, 2017). En el abordaje noticioso sobre los resultados educativos se rehúye la profundidad y la rigurosidad que deberían tener temas tan trascendentes como las evaluaciones educativas. Las representaciones mediáticas construidas se sitúan en una acción promocional o propagandística de los hechos cotidianos y producidos institucionalmente, sin articular la diversidad contextual en el análisis (Horta, 2013), que aportaría a la descodificación de los contenidos informados. Las noticias abordadas propician la unicidad de ideas como signo visible de la homogeneización del pensamiento, imponiendo una racionalidad de consumo simbólico como evidencia implícita o explícita de los posicionamientos mediáticos.

Visto el panorama del tratamiento mediático de los resultados educativos, resulta de interés para la realidad peruana explorar y analizar el énfasis priorizado en las noticias periodísticas que abordan los resultados de las evaluaciones en las que participa el sistema educativo nacional, a fin de reconocer su coherencia y el sentido compartido con la audiencia pública. Este estudio se orienta a reconocer cómo se configura la mediatización de los resultados educativos, qué aspectos se priorizan, se infieren y se reflejan en determinadas prácticas 
sociales. En esencia, qué tratamientos informativos se privilegian en la construcción de la noticia, cómo se instituyen desde la prensa a modo de conocimientos y creencias para el manejo de la opinión pública, dado que la prensa resalta en algunos textos o unidades de significación noticias que legitiman y reproducen como «ideas» hegemónicas y como síntesis de una pluralidad de voces resultantes de la (re)lectura y adaptaciones.

\section{Método}

La investigación se dirigió hacia el análisis del tratamiento informativo de las noticias publicadas por la prensa peruana sobre los resultados de las pruebas de medición del aprendizaje, es decir, a través del método de análisis de contenido discursivo se abordaron los aspectos relevantes en las representaciones mediáticas que enfatizaba la prensa nacional. Básicamente se orientó a reconocer los distintos rasgos de la representación discursiva de la noticia, materializada a través de los diferentes géneros periodísticos. En esa intención se buscó la «inferencia de conocimientos relativos a las condiciones de producción (o eventualmente de recepción), con ayuda de indicadores (cuantitativos o no)» (Bardin, 1986, p. 29).

Para avanzar en dicho propósito se seleccionaron las notas periodísticas sobre las evaluaciones internacionales y nacionales. La información periodística recuperada, según la temporalidad especificada en la tabla 1 , constituyó el corpus de análisis, considerando los aspectos cuantificables del contenido de los textos periodísticos (Titscher, Meyer, Wodak y Vetter, 2002) y la generación de un sistema de categorías de los datos analizados (Savolainen, 2010) a partir del siguiente interrogante: ¿qué estrategias de representación mediática elabora la prensa nacional en el tratamiento informativo de los resultados educativos?

\subsection{Objeto y muestra de estudio}

Los objetos concretos del estudio se basaron en las noticias periodísticas referidas a los resultados de las pruebas internacionales PISA 2015 y TERCE 2013, así como a los de la prueba nacional ECE 2016, publicadas en la versión digital de los principales diarios impresos (CPI, 2016). Los criterios de recuperación incluyeron noticias de diverso género periodístico (informativo, interpretativo y de opinión). Para la búsqueda de información se definieron como descriptores de búsqueda: «PISA+2015», «TERCE+2015» y «ECE+2016», que, introducidos en los repositorios digitales de los diarios, dieron los resultados que se detallan a continuación (tabla 1).

La tabla 1 sintetiza el corpus del estudio, puesto que reúne artículos desde la fecha de publicación hasta la última noticia publicada. Los resultados organizados evidencian el predominio informativo de la prueba PISA, un alcance mediano de la prueba nacional ECE y un marcado desinterés por la evaluación latinoamericana TERCE. Asimismo, las noticias muestran la duración de las 
publicaciones, lo que indica su interés. A PISA los medios le dedican casi tres meses; a ECE, algo más de un mes, y a TERCE, escasamente cinco días.

La muestra de estudio fue organizada en función de los elementos de la noticia (tabla 2). En su selección se considera la estructura de las notas periodísticas.

Tabla 1. Población y muestra de noticias publicadas en los principales diarios impresos peruanos en versión digital

\begin{tabular}{|c|c|c|c|c|c|c|}
\hline \multirow[t]{2}{*}{$\begin{array}{l}\text { Publicación } \\
\text { periodística }\end{array}$} & \multicolumn{2}{|c|}{$\begin{array}{c}\text { PISA 2015 } \\
\text { (del 7/12/2016 } \\
\text { al 28/2/2017) }\end{array}$} & \multicolumn{2}{|c|}{$\begin{array}{l}\text { TERCE } 2013 \\
\text { (del 6/8/2015 } \\
\text { al 10/8/2015) }\end{array}$} & \multicolumn{2}{|c|}{$\begin{array}{c}\text { ECE } 2016 \\
\text { (del } 9 / 4 / 2017 \\
\text { al } 16 / 5 / 2017 \text { ) } \\
\end{array}$} \\
\hline & Población & Muestra & Población & Muestra & Población & Muestra \\
\hline El Comercio & 16 & 6 & 2 & 2 & 6 & 4 \\
\hline Perú21 & 14 & 5 & 2 & 2 & 5 & 4 \\
\hline Correo & 14 & 4 & 1 & 1 & 5 & 2 \\
\hline La República & 17 & 6 & 2 & 2 & 6 & 3 \\
\hline Gestión & 13 & 4 & 1 & 1 & 4 & 2 \\
\hline Diario Uno & 9 & 4 & 0 & 0 & 3 & 2 \\
\hline TOTAL & 83 & 29 & 8 & 8 & 29 & 17 \\
\hline
\end{tabular}

Fuente: elaboración propia.

Tabla 2. Muestra de noticias organizadas según los elementos que la componen

\begin{tabular}{|c|c|c|c|c|}
\hline Estructura & Elementos de la estructura periodística & $\begin{array}{l}\text { PISA } \\
2015\end{array}$ & $\begin{array}{c}\text { TERCE } \\
2013\end{array}$ & $\begin{array}{l}\text { ECE } \\
2016\end{array}$ \\
\hline \multirow[t]{3}{*}{ Titular } & Antetítulo & 28 & 3 & 15 \\
\hline & Titulo & 29 & 8 & 17 \\
\hline & Subtitulo & 20 & 0 & 11 \\
\hline \multirow{3}{*}{$\begin{array}{l}\text { Cuerpo de } \\
\text { la noticia }\end{array}$} & Entradilla (resumen de la síntesis informativa) & 25 & 4 & 4 \\
\hline & Datos relevantes (párrafos que desarrollan la noticia) & 17 & 5 & 11 \\
\hline & Datos complementarios (estadísticos, infografías) & 7 & 2 & 5 \\
\hline
\end{tabular}

Fuente: elaboración propia.

La selección de la muestra (notas informativas) considera los textos de mayor significación sobre los resultados educativos, es decir, la extensión, la explicación y el detalle de las noticias. En ese sentido, las notas elegidas representan los énfasis asignados a la construcción de los textos, es decir, expresan el tratamiento seguido, tanto en los titulares como en el cuerpo del artículo.

La tabla 2 distingue tratamientos y abordajes diferenciados en la representación de la información, donde sobresalen ampliamente las noticias sobre PISA en comparación con TERCE. Asimismo, el relato noticioso es más explícito en PISA, regularmente en ECE y muy exiguo en TERCE. De ese modo responden a un patrón informativo condicionado. 


\subsection{Procedimiento de análisis de los datos}

El procedimiento contempló la organización crítica de la información contenida en las noticias, organizadas a partir de variables informativas y estructuradas en categorías de respuesta, así como la frecuencia asociada a ellas.

1. Presencia mediática de los resultados educativos, según género periodístico.

2. Construcción mediática de los resultados educativos, según sentido informativo.

3. Mensajes implícitos del tratamiento informativo de los resultados educativos.

Tabla 3. Organización temática de la información recuperada sobre los resultados educativos

\begin{tabular}{lllll}
\hline $\mathbf{N} .^{\circ}$ & Variable & Categorías & Descripción & Frecuencia \\
\hline 1 & $\begin{array}{l}\text { Presencia mediática de } \\
\text { la prueba de evaluación } \\
\text { (internacional/nacional) }\end{array}$ & Informativo & $\begin{array}{l}\text { Relato objetivo y } \\
\text { directo }\end{array}$ \\
& Opinión & Información opinada \\
\hline $\begin{array}{l}\text { Construcción mediática } \\
\text { de los resultados } \\
\text { educativos }\end{array}$ & Análisis de resultados & $\begin{array}{l}\text { Valoración personal } \\
\text { Custificación de los } \\
\text { cambios }\end{array}$ & $\begin{array}{l}\text { Efectos } \\
\text { Educativos }\end{array}$ \\
$\begin{array}{l}\text { Mensajes implícitos del } \\
\text { tratamiento informativo } \\
\text { de los resultados } \\
\text { educativos }\end{array}$ & Sintetiza la realidad & Políticos \\
\hline
\end{tabular}

Fuente: elaboración propia.

Luego de la tabulación de los datos analizados se procedió a realizar una interpretación cualitativa de los contenidos, remitiendo a notas periodísticas recuperadas, a fin de estructurar los modelos de representación que explicitan la priorización de determinadas características.

\section{Resultados}

Los medios periodísticos reproducen formas de entender y de propagar la información, construyendo representaciones mediáticas que forman la opinión pública. En el tratamiento informativo de los resultados educativos, dadas las controversias, se configuran determinados énfasis y omisiones, revelando tendencias priorizadas y difundidas más ampliamente. 


\subsection{Presencia mediática de los resultados educativos}

Los resultados de la organización de la información muestran que la prensa nacional destaca en su visibilización noticiosa a una de las pruebas internacionales y relega a la otra. El énfasis expresa una percepción condicionada y orientada a incitar en la opinión pública una mayor inquietud sobre ese tema, evidenciando la primacía mediática de un hecho.

Figura 1. Presencia mediática de los resultados educativos en la prensa peruana según género periodístico (\%)

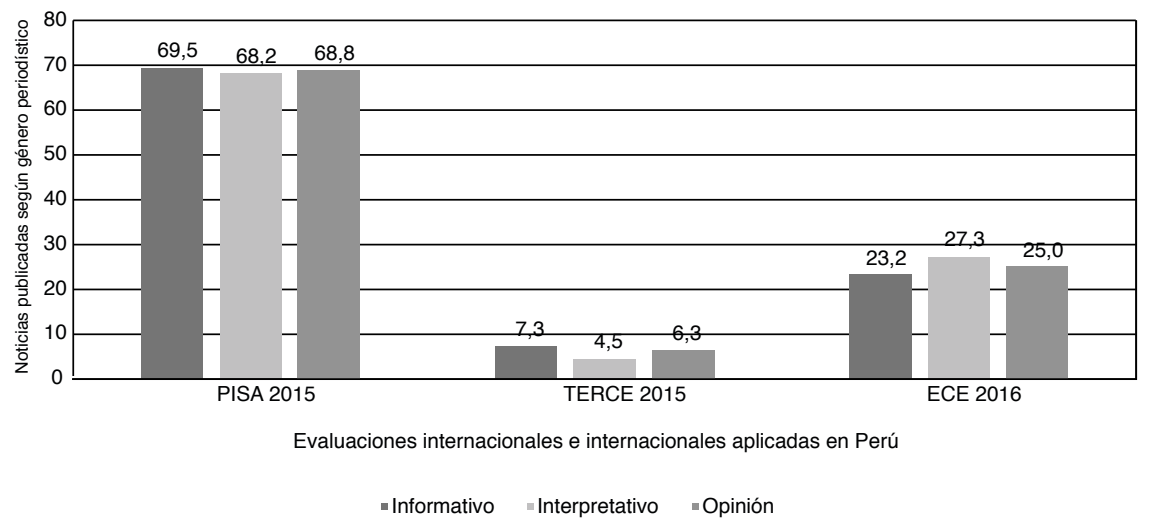

Fuente: elaboración propia.

Básicamente, las representaciones mediáticas construidas buscan exaltar la información sobre el fracaso educativo que relata PISA 2015 (un 69,5\%). Complementan la preeminencia noticiosa de PISA con la relegación de las pruebas ECE (un 23,2\%) y TERCE (un 7,3\%). Ello las convierte en irrelevantes, carentes de impacto y sin mayor valor de uso educativo, lo que en instancias últimas desmerece su esencialidad. De ese modo, la construcción de la información noticiosa sitúa a la prueba PISA como representación de la medida del sistema educativo nacional, un mensaje dirigido convenientemente por la prensa y que sirve para instalar una apoteosis noticiosa, sin mayores discrepancias ni profundidad comprensiva.

Las situaciones representadas mediáticamente tienen un propósito explícito: posesionar la preponderancia de PISA como referencia válida de los acontecimientos educativos. En la ingente concentración noticiosa de PISA prima sobre todo el género informativo, puesto que en ella subyace el sentido de constreñir el reconocimiento «real» del sistema educativo. De otro lado, el carácter predominante de lo informativo presupone una banalización de los resultados, de relevar solo lo «noticiable», una suerte de fetichización de PISA como única referencia de medida de «lo correcto». 


\subsection{Construcción noticiosa de las representaciones mediáticas}

Los encuadres de la información periodística resaltan las inferencias generadas, mostrando la relevancia del tratamiento noticioso al destacar y valorar las ideas que consideran de mayor representación mediática, aproximando subjetivamente a la audiencia a un espectro mayor de consumo informativo como relación social predominante.

Tabla 4. Construcción mediática de los resultados educativos según el sentido informativo (\%)

\begin{tabular}{lcccccc}
\hline \multirow{2}{*}{ Prueba } & \multicolumn{5}{c}{ Aporte informativo de los resultados educativos } \\
\cline { 2 - 7 } & Análisis de resultados & Justificación de los cambios & Sentido comparativo \\
\cline { 2 - 7 } & Causas & Efectos & Educativos & Políticos & Interno & Externo \\
\hline PISA 2015 & 24 & 76 & 63 & 37 & 21 & 79 \\
\hline TERCE & 69 & 31 & 36 & 64 & 32 & 68 \\
2013 & & 44 & 58 & 42 & 65 & 35 \\
\hline ECE 2016 & 56 & 44 &
\end{tabular}

Fuente: elaboración propia.

Los aportes noticiosos sobre los resultados educativos permiten apreciar los énfasis informativos. En el tratamiento mediático de la prensa peruana sobresalen PISA, con noticias centradas en sus efectos (un 76\%), al referir las consecuencias que afligen al sistema educativo nacional. En torno a TERCE (un 31\%) y ECE (un 44\%) muestran un orden distinto, puesto que priman más las causas. Es sabido que los efectos dependen de las causas y que las causas producen efectos. Esta circularidad del conocimiento no es abordada por la prensa nacional, dado que resalta los efectos obviando las causas y acentuando los fracasos: "mejoró pero continúa en los últimos lugares», "hay un $46,7 \%$ de escolares peruanos que se ubican entre los que obtienen los peores resultados», "una brecha reducida insuficientemente».

El tipo de tratamiento mediático soslaya las raíces del problema (las causas), es decir, las limita a un conjunto de manifestaciones al señalar «sin mayores progresos en PISA». Tales interpretaciones forman, en el imaginario popular y en ciertos sectores de gobierno, la necesidad de generar cambios. Los medios señalan que solo «un $0,6 \%$ alcanza los más altos niveles de educación», lo que evidencia la preeminencia noticiosa sobre PISA y minimiza los avances que, según TERCE y ECE, se expresan en la constatación de que «la brecha entre nuestro país y sus pares latinoamericanos se ha reducido", una información relegada intencionalmente por la prensa. Mediante la selección de noticias que justifican intervenciones no siempre concordantes con la realidad nacional, la exacerbación mediática de PISA la posesiona como referencia para plantear cambios pedagógicos (un 67\%), al resaltar el relato del desastre educativo y de que Perú representa al peor sistema de enseñanza del mundo.

Las noticias sobre los resultados educativos de las pruebas internacionales y nacionales expresan, igualmente, posibilidades comparativas. Las representaciones mediáticas en torno a PISA son de favorecimiento al contexto exter- 
no (un 79\%) y de demérito al interno: «Perú continúa en los últimos lugares», «ocupó el puesto 64 de 70». En el caso de TERCE, si bien compara países latinoamericanos, su tratamiento mediático no resulta tan enfático como PISA. Y respecto a ECE, la prueba nacional, la centralidad de su análisis es más interna, y sobre ello la prensa no ahonda en mayores aspectos que los correspondientes a la noticia, inhibiendo una compresión más próxima de los hechos.

\subsection{Los mensajes implícitos de los resultados educativos}

El carácter implícito de la noticia se verifica mediáticamente, desde «las formas más elementales, como pueden ser las ironías o las metáforas, hasta formas más complejas y sutiles» (Ruiz, 2014, p. 172). Las representaciones mediáticas permiten comprender el sentido discursivo y, deliberadamente, inhiben la crítica y los contraargumentos, al provocar «cortocircuitos» en la deliberación pública y enfatizar en el sensacionalismo a través de sesgos mediáticos (Botrel, 2016; Turpo-Gebera, 2018b).

Tabla 5. Mensajes implícitos del tratamiento informativo de los resultados educativos (\%)

\begin{tabular}{lllll}
\hline \multirow{2}{*}{ Prueba } & \multicolumn{2}{c}{ Valoración de los mensajes implícitos de los resultados educativos (\%) } \\
\cline { 2 - 5 } & \multicolumn{2}{c}{ Sintetiza la realidad } & \multicolumn{2}{c}{ Factores «noticiables» } \\
\cline { 2 - 5 } & Sí (Formalismo) & No (Sensacionalismo) & Desequilibrios & Instigaciones \\
\hline PISA 2015 & 22 & 78 & 45 & 55 \\
TERCE 2013 & 82 & 18 & 44 & 56 \\
\hline ECE 2016 & 43 & 57 & 57 & 43 \\
\hline
\end{tabular}

Fuente: elaboración propia.

El tratamiento mediático de los resultados educativos por parte de la prensa nacional patentiza la construcción sensacionalista de las noticias sobre PISA 2015 (un 78\%) y ECE 2016 (un 57\%), mientras que en TERCE 2013 (un $18 \%$ ) prima la formalidad periodística. En torno a PISA 2015 resalta el sensacionalismo, el morbo del "fracaso» educativo, de crisis, de los «últimos de la lista» (ranking), lo que induce a la banalización del esfuerzo educativo. En ese entender todo lo válido se reduce a lo representado por PISA. Los mensajes forjan un sentimiento de inferioridad que conduce a la conmoción, al resaltar noticias como "los peores resultados a nivel mundial», "aún sigue en la cola», "no mejora ni en lectura ni en matemática, y ligeramente en ciencias» $\mathrm{y}$ «desajustes entre lo rural y lo urbano». Una impresión que sobrecoge el sentir nacional, "vehiculizando» la crisis de la educación como una situación de catástrofe.

En PISA 2015 las representaciones mediáticas tienden a la exageración de resultados, al comparar las insuficiencias académicas: «ubicándose en el puesto 63 de 69 países», «un puesto mejor respecto a la prueba de 2012», «no levanta cabeza». La exaltación noticiosa del fracaso construye una narrativa del protagonismo sobre PISA, de medida del éxito. Tales representaciones expre- 
san la manipulación y las artimañas para situar la atención mediática a través de la pérdida de objetividad y el reduccionismo informativo, al despreciar la evolución de los hechos y solo resaltar los resultados nocivos, desmereciendo representaciones más "auténticas» de los avances y los cambios del sistema educativo nacional.

Los factores que suscitan la noticiabilidad de la información responden a los «valores noticia» que permiten a los aparatos informativos controlar y gestionar la cantidad y el tipo de acontecimientos noticiables. En PISA y ECE se acentúa lo denigrante y el negativismo de los resultados: «no hay nada que celebrar ni se debe abrir el champagne», "presenta mejoras, pero aún sigue en la cola», «la [escuela] pública supera ligeramente a la privada», «se ubicó en el último puesto de los 65 países participantes». El sentido asignado por las representaciones mediáticas privilegia los desequilibrios o desajustes, así como lo trivial, desnaturalizando el sentido de la educación.

\section{Conclusiones}

El estudio evidencia que la prensa nacional representa mediáticamente los resultados de las pruebas internacionales y nacionales con diferente énfasis. Básicamente, los medios privilegian determinadas formas de construir la noticia, para resaltarlas por encima de otras. La preeminencia establecida busca circunscribir el hecho educativo a los dictámenes de la OCDE (GonzálezMayorga, Vidal y Vieira, 2017; Leibfried y Martens, 2009; Runte-Geidel, 2016; Turpo-Gebera, 2018a), de ahí el énfasis mediático asignado a PISA y el solapamiento de las otras pruebas, ECE y TERCE, igualmente importantes para conocer el estado integral del sistema educativo nacional. La alta cantidad de información dedicada a PISA busca rubricar el sentido hegemónico asignado a dicha prueba, al incidir y destacar los lugares que los países ocupan en la tabla de clasificación (Luzón y Torres, 2013).

La extensión de la noticia sobre los resultados educativos, en cobertura y formato, tanto como su continuidad temporal, expresan un posicionamiento a favor de PISA en desmedro de TERCE y ECE. Para Ferrer (2012), la priorización mediática buscaría instituir políticas de una instancia supranacional, como la OCDE, como referencia única y válida para todos los contextos, una forma de estandarización que llevaría a una sola manera de entender la educación. Tales representaciones responden a tratamientos informativos dirigidos a orientar a la audiencia hacia una selección antojadiza que exalte la superioridad de PISA (García, Ruiz y Serrano, 2018), a través de datos o textos noticiables donde recalcan mediáticamente, según Ruiz (2014), las intenciones, la extensión o la generalización de lo estimado como representativo y referencia de comprensión del problema educativo. Una intervención construida intencionadamente.

El tratamiento informativo de resaltar solo lo noticiable responde a una creciente mediatización y politización de las evaluaciones educativas (Bottani, 2006; Couldry, 2012; Rawolle y Lingard, 2010) que favorecen el valor de uso 
de la noticia, de resaltar representaciones ampliadas del fracaso formativo, de estimaciones del déficit educativo y desvalorización de los avances pedagógicos. Es indudable que la búsqueda y la presentación de la noticia signa los análisis periodísticos, pero la ausencia de un sentido crítico y reflexivo los sitúa en una presencia superficial y sesgada que parece estar encaminada a «amplifica[r] todo cuanto arroja una imagen negativa del sistema escolar del país» (Pedró, 2012, p. 142). En esa línea, se edifica una «imagen» asolada y devastada de la educación peruana, de la frustración como característica sobresaliente (TurpoGebera, 2018a). La situación representada, como afirman Dixon, Muller, Arndt y Hood (2008), «domina» el panorama mediático, creando un impacto que sirve para posicionar a determinados actores de la política educativa, para sugerir reformas no siempre convenientes para el país y promover una mayor neoliberalización de la educación, léase "privatización».

La presencia discursiva de los resultados educativos es inducida mediáticamente y resulta tan preponderante la tendencia (obscena) por resaltar a PISA que, como señala Grek (2009), cualquier emprendimiento educativo debería hacerle alguna referencia para ser significativamente considerable. La primacía mediática construida por la prensa nacional, al igual que en otras latitudes, según Hopmann, Brinek y Retzl (2007), desplaza al discurso político hacia una insustituible consideración hacia los resultados de las evaluaciones PISA como única referencia o medida de lo que acontece en educación. Un sesgo mediático que sume a la audiencia en la pérdida de un derrotero nacional, sumergiéndola en el escándalo, la postergación y la desidia, básicamente en la irrelevancia informativa (Capellini, 2004). Este énfasis desmerece las peculiaridades de los sistemas educativos, al basar su información en los lugares que ocupan los países en la clasificación, desnaturalizando el sentido de educar, que no está solo en ocupar lugares privilegiados, pues sería reducir la educación a «un número carente de significado por no tener ningún contexto» (Munguía, 2019, p. 46).

En el proceso interpretativo los medios periodísticos nacionales recurren al sensacionalismo de la noticia para «vehiculizar» la situación de catástrofe del sistema educativo peruano, suscitando un estado de alarma educativa que induce a «lecturas» parciales, poco profundas o interesadas, revestidas de efectismo o burdamente erradas (Munguía, 2019). De ese modo, se busca normalizar los discursos hegemónicos (Cabalin, Montero y Cárdenas, 2019). La atención notoria y sórdida hacia las noticias sobre PISA, que la mayoría mediática representa como conocimiento "verdadero», construye una forma de comprensión del fenómeno educativo, muy difundida entre la población y que no necesariamente es la más apropiada para entenderla (Báez Martín, 2016; Ferrer, Massot y Ferrer, 2006; Rodrigo, 2015; Turpo-Gebera, 2018a). Estos mensajes instalan en la población un sistema implícito de valoración que responde a una inadecuada comprensión (Rodrigo, 2015) y que se asumen como «certezas» sobre la educación peruana. Olvidan, así, que las recomendaciones de PISA, dada «su nula función diagnóstica del desempeño individual del alumno» (Fernández-Cano, 2016, p. 12), podrían conducir a inferencias no siempre válidas. 
En esencia, las estimaciones noticiosas sobre los resultados educativos resaltan sobre todo lo coyuntural y noticiable, no promueven movilizaciones ciudadanas de reflexión acerca del valor real de la educación. Los medios de prensa nacional parecen ceñirse a unas determinadas agendas sobre problemas priorizados, más que a fundamentar una agenda de cambios favorables a la dinámica nacional, lo que sería un conocimiento más útil para establecer cambios fundamentados. Por el contrario, se persiste en sojuzgar el valor de los avances educativos, situándola dentro de una visión economicista, en valorar más los resultados del ranquin y no las diferencias, exaltando como necesario un nuevo desarrollo educativo donde se efectivicen los aprendizajes como aspectos claves para el desarrollo social y económico (Colella y Díaz, 2017; Urteaga, 2010). Asumen, así, la incidencia mediática de los malos resultados, utilizados ampliamente en las noticias sobre PISA 2015 como argumentos para la necesidad de realizar una reforma educativa (Báez Martín, 2016).

\section{Referencias bibliográficas}

Báez Martín, Y. (2016). PISA en la prensa escrita de los diarios tinerfeños. Tesis de máster. Universidad de La Laguna. España.

Baltazar, P. y Gargurevich, J. (2017). Balance analítico de la cobertura de los medios de comunicación en temas de gestión educativa descentralizada. En ForGe-GRADE (coord.). ¿Cómo abordan los medios la educación en el Perú? (pp. 51-71). Lima: FORGE-GRADE.

Bardin, L. (1986). El análisis de contenido. Madrid: Akal.

Baudelot, C. y Leclerco, F. (dirs.) (2008). Los efectos de la educación. Buenos Aires: Del Estante.

Botrel, J. (2016). El sensacionalismo en la era premediática. En C. Almuiña, R. Martín de la Guardia y J. Pelaz (coord.). Sensacionalismo y amarillismo en la historia de la comunicación (pp. 25-40). Madrid: Fragua.

Bottani, N. (2006). La más bella del reino: El mundo de la educación en alerta con la llegada de un príncipe encantador. Revista de Educación, núm. extra 1, 75-90.

Bowe, R.; BALL, S. y Gold, A. (1992). Reforming education and changing schools: Case studies in policy sociology. Londres: Routledge.

Bustamante, R. (2017). Balance analítico de la cobertura de los medios de comunicación en temas de Educación Intercultural Bilingüe. En Forge-Grade (coord.). ¿Cómo abordan los medios la educación en el Perú? (pp. 7-20). Lima: FORGEGRADE.

Cabalin, C. y Antezana, L. (2016). La educación en portada: La visualización de la política educacional en la prensa. Cuadernos.info, 39, 195-207. <http://dx.doi.org/10.7764/cdi.39.914>

Cabalin, C.; Montero, L. y Cárdenas, C. (2019). Discursos mediáticos sobre la educación: El caso de las pruebas estandarizadas en Chile. Cuadernos.info, 44, 135-154. $<$ http://dx.doi.org/10.7764/cdi.44.1429>

Capeluini, M. (2004). La prensa «chicha» en el Perú. Chasqui: Revista Latinoamericana de Comunicación, 88, 32-37. 
Carmona, J. y Jaimes, M. (2015). Desigualdad ambiental y desigualdad comunicacional: Las portadas de El Mercurio de Valparaíso sobre el derrame de petróleo en la bahía de Quintero. Cuadernos.info, 36, 71-87. <http://dx.doi.org/10.7764/cdi.36.734>

Colella, L. y Díaz, R. (2017). Análisis de la calidad educativa en el discurso neoliberal. Educar, 53(2), 447-465. $<$ http://dx.doi.org/10.5565/rev/educar.749>

Compañía Peruana de Estudios de Mercados y Opinión Pública SAC (CPI) (2016). Estudio de lectoría de diarios en Lima y 15 principales ciudades - 2016. Recuperado de <http://cpi.pe/images/upload/paginaweb/archivo/23/Lectoria Diarios_2016.pdf>.

Couldry, N. (2012). Media, society, world: Social theory and digital media practice. Cambridge, MA: Polity Press.

Díaz-Nosty, B. (2015). La banalización del periodismo. Cuadernos de Periodistas, 31, 9-17.

Dixon, R.; Muller, M.; Arndt, C. y Hood, C. (2008). Where International Rankings Meet Neativity Bias: Domestic Press Responses to International Educational Rankings in Three EU Countries. Universidad de Oxford. Recuperado de <http:// www.christopherhood.net/pdfs/posterintrankings.pdf>.

Esser, F. у Sтröмвӓск, J. (eds.) (2014). Mediatization of politics: Understanding the transformation of western democracies. Nueva York: Palgrave Macmillan.

Fernández-Cano, A. (2016). Una crítica metodológica de las evaluaciones PISA. RELIEVE: Revista ELectrónica de Investigación y EValuación Educativa, 22(1). <http://dx.doi.org/10.7203/relieve.22.1.8806>

FErrer, J. (2012). PISA: Aportaciones e incidencia sobre las políticas educativas nacionales. Revista Española de Educación Comparada, 19, 11-16. <http://dx.doi.org/10.5944/reec.19.2012.7941>

Ferrer, J.; Massot, M. y Ferrer, G. (coord.) (2006). Percepciones y opiniones desde la comunidad educativa sobre los resultados del proyecto PISA. Madrid: MECCIDE.

García, E.; Ruiz San Román, J. y Serrano, J. (2018). Google es noticia: Transformación de los marcos informativos sobre Google en la prensa española. Icono 14, $16(2), 27-50$. <http://dx.doi.org/10.7195/ri14.v16i2.1158>

González-Mayorga, H.; Vidal, J. y Vieira, M. (2017). El impacto del Informe PISA en la sociedad española: El caso de la prensa escrita. RELIEVE: Revista ELectrónica de Investigación y EValuación Educativa, 23(1). <http://dx.doi.org/10.7203/relieve.23.1.9015>

Grek, S. (2009). Governing by numbers: The PISA 'effect' in Europe. Journal of Education Policy, 24(1), 23-37. <http://dx.doi.org/10.1080/02680930802412669>

HJarvard, S. (2013). The mediatization of culture and society. Nueva York: Routledge.

Hopmann, S.; Brinek, G. y Retzl, M. (eds.) (2007). PISA zufolge PISA - PISA according to PISA. Hält PISA, was es verspricht? - Does PISA Keep What It Promises? Berlín: Lit Verlag.

Horta, J. (2013). Representaciones mediáticas: Tres notas sobre los procesos semióticos en los medios masivos. Comunicación y Medios, 28, 96-112. <http://dx.doi.org/10.5354/0719-1529.2014.27085> 
KoH, A. (2009). The visualization of education policy: A videological analysis of Learning Journeys. Journal of Education Policy, 24(3), 283-315. <http://dx.doi.org/10.1080/02680930802669946>

Leibfried, S. y Martens, K. (2009). PISA: Internacionalización de la política educativa o ¿cómo se llega de la política nacional a la OCDE? Profesorado: Revista de Curriculum y Formación del Profesorado, 13(2). Recuperado de <https://recyt.fecyt. es/index.php/profesorado/article/view/42333/24274>.

Lingard, B. (2016). Think Tanks, 'policy experts' and 'ideas for' education policy making in Australia. The Australian Educational Researcher, 43(1), 15-33. $<$ http://dx.doi.org/10.1007/s13384-015-0193-0>

Luzón, A. y Torres, M. (2013). La presencia de PISA en la literatura científica y su tratamiento en la prensa diaria internacional. Profesorado: Revista de Curriculum y Formación del Profesorado, 17(2), 193-224.

Mateos, M. y Gaona, C. (2018). Crisis del Estado del bienestar: Estrategias de hegemonía desde el discurso mediático. Chasqui: Revista Latinoamericana de Comunicación, 137, 391-411.

Munguía, M. (2019). El informe PISA 2015: Un análisis de los resultados, la metodología y el impacto en los medios de comunicación. Tesis de máster. Universidad de Cantabria. España

Pedró, F. (2012). Deconstruyendo los puentes de PISA: Del análisis de resultados a la prescripción política. Revista Española de Educación Comparada, 19, 139172. $<$ http://dx.doi.org/10.5944/reec.19.2012.7581>.

Poop, R. y Mendelson, A. (2010). X-ing out enemies: Time magazine, visual discourse, and the war in Iraq. Journalism, 11(2), 203-221. $<$ http://dx.doi.org/10.1177/1464884909355913>

Ravela, P. (2006). Los resultados de las evaluaciones educativas en la prensa. En P. ARregui (ed.). Sobre estándares y evaluaciones en América Latina (pp. 295-384). Santiago de Chile: PREAL.

Rawolle, S. y Lingard, B. (2010). The mediatization of the knowledge based economy: An Australian field based account. Communications: The European Journal of Communications Research, 35(3), 269-286. $<$ http://dx.doi.org/10.1515/COMM.2010.015>

Reguillo, R. (2007). Formas de saber: Narrativas y poderes diferenciales en el paisaje neoliberal. En A. Grimson (ed.). Cultura y neoliberalismo (pp. 91-110). Buenos Aires: CLACSO.

Rodrigo, L. (2015). El uso público del programa PISA en Argentina: Entre los medios de comunicación y la administración educativa. En H. MonarCA (coord.). Evaluaciones externas: Mecanismos para la configuración de representaciones y prácticas en educación (pp. 129-152). Buenos Aires: Miño y Dávila.

- (2019). Los programas internacionales de evaluación estandarizada y el tratamiento de sus datos a nivel nacional: El caso de Argentina en el estudio PISA de la OCDE. Foro de Educación, 17(26), 73-94. $<$ http://dx.doi.org/10.14516/fde.708>

Rodrigo-Alsina, M. y Lazcano-Peña, D. (2014). La enseñanza en Comunicación y su proceso de adaptación al EEES como objeto de estudio: Una visión panorámica. Communication \& Society, 27(2), 221-239.

RodríGuez, R. (2005). México en los resultados PISA 2003: Una interpretación no catastrofista. Revista Mexicana de Investigación Educativa, 10(24), 255-266. 
Ronzani, T.; Fernandes, A.; Gebara, C.; Oliveira, S.; Scoralich, N. y Lourenço, L. (2009). Mídia e drogas: Análise documental da mídia escrita brasileira sobre o tema entre 1999 e 2003. Ciência \& Saúde Coletiva, 14(5), 1751-1762. <http://dx.doi.org/10.1590/S1413-81232009000500016>

Ruiz, J. (2014). El discurso implícito: Aportaciones para un análisis sociológico. Revista Española de Investigaciones Sociológicas, 146, 171-190. <http://dx.doi.org/10.5477/cis/reis.146.171>

Ruiz, J.; BräNdLE, G. y CÁCERES, M. (2017). Estudio de variables relevantes en el uso de la información publicada por los organismos públicos en Internet: Una reivindicación de la mediación periodística, Icono 14, 15(2), 137-157. <http://dx.doi.org/10.7195/ri14.v15i2.1068>

Runte-Geidel, A. (2016). PISA en la prensa española y su influencia sobre las políticas educativas. Opción: Revista de Ciencias Humanas y Sociales, 32(8), 713-733.

SAnTa Cruz, L. (2016). Mediatización de las políticas educativas en Chile: El discurso de los diarios La Tercera y El Mercurio sobre la Ley General de Educación (2006-2009). Tesis doctoral. Universidad de Granada, España.

Santa Cruz, E. y Olmedo, A. (2012). Neoliberalismo y creación del 'sentido común': Crisis educativa y medios de comunicación en Chile. Profesorado: Revista de Currículum y Formación del Profesorado, 16(3), 145-168.

SaVOlainen, R. (2010). Dietary blogs as sites of informational and emotional support. Information research, 15(4). Recuperado de <http://InformationR.net/ir/15-4/ paper438.html>.

Titscher, S.; Meyer, M.; Wodak, R. y Vetter, E. (2002). Methods of text and discourse analysis. Londres: Sage.

Turpo Gebera, O. (2018a). Representaciones de resultados educativos: PISA 2015 en medios digitales peruanos. Espacios, 39(5). Recuperado de <http://www.revis taespacios.com/a18v39n05/18390516.html >.

- (2018b). Tratamiento informativo de la huelga magisterial en la prensa peruana. Revista Lasallista de Investigación, 15(2), 232-245. <http://dx.doi.org/10.22507/rli.v15n2a18>

Urteaga, E. (2010). Los resultados del estudio PISA en Francia. Revista Complutense de Educación, 21(2), 231-244.

Vasilachis de Gialdino, I. (1997). Discurso Político y prensa escrita. Barcelona: GEDISA.

Verón, E. (1997). Esquema para el análisis de la mediatización. Diálogos de la Comunicación, 48, 9-17.

- (1998). Interfaces: Sobre la democracia audiovisual evolucionada. En J. FERrY, D. Wolton et al. (eds.). El nuevo espacio público (pp. 124-126.). Barcelona: GEDISA. 